\title{
REFLEXÕES ACERCA DA ORIGEM DO LIBERALISMO E DO DIREITO NO ESTADO MODERNO
}

\author{
Elaine Gomes Ferro ${ }^{1}$, Jorge Luís Mazzeo Mariano \\ Universidade Estadual Paulista - UNESP. ${ }^{1}$ Mestranda em Educação - Programa de Pós-Graduação em Educação, \\ Presidente Prudente - SP. ${ }^{2}$ Doutorando em Educação - Programa de Pós-Graduação em Educação, Presidente \\ Prudente-SP. E-mail: elainegferro@uol.com.br
}

\section{RESUMO}

O presente artigo é fruto de uma pesquisa teórica que tem como objetivo central a tentativa de estabelecer uma discussão acerca do surgimento do liberalismo enquanto doutrina filosófica do capitalismo no contexto de lutas da classe burguesa, entre os séculos X e XVIII. Em relação aos resultados, abordou-se algumas das consequências das lutas burguesas e a afirmação do pensamento liberal como base filosófica do capitalismo. Enfatiza-se na discussão que essas lutas fomentaram a criação do Estado Moderno e da noção de cidadania. Ao final do texto se conclui que apesar da importância do liberalismo para a conquistas dos chamados direitos individuais, observa-se, em última instância, uma negação dos chamados direitos sociais, esses entendidos no atual contexto como mercadorias.

Palavras-chave: liberalismo; burguesia; Estado Moderno; cidadania; direitos.

\section{REFLECTIONS ON THE ORIGIN OF LIBERALISM AND THE LAW IN MODERN STATE}

\begin{abstract}
This article is based on a theoretical research that has as its central objective the attempt to establish a discussion of the emergence of liberalism as a philosophical doctrine of capitalism in the context of the bourgeois class struggles between $\mathrm{X}$ and XVIII centuries. It is emphasized in discussion that these struggles fostered the creation of the modern state and the notion of citizenship. Regarding the results, we discussed some of the consequences of bourgeois struggles and the affirmation of liberal thought as a philosophical basis of capitalism. At the end of the text concludes that despite the importance of liberalism called for the achievements of individual rights, it is observed, ultimately a denial of so-called social rights, these understood in the present context as commodities.
\end{abstract}

Keywords: liberalism; bourgeoisie; Modern State; citizenship; rights. 
INTRODUÇÃO

Discute-se brevemente neste artigo como o capitalismo surgiu e se desenvolveu paralelamente à burguesia, numa relação mútua e em um contexto em que a referida classe buscava a liberdade para o exercício comercial e, consequentemente, o estabelecimento das raízes do posterior domínio político - consolidado somente a partir da Revolução Francesa.

Deste modo, o principal objetivo do artigo é estabelecer uma discussão acerca do surgimento do liberalismo no contexto de formação dos Estados Nacionais fomentado pela burguesia tendo como uma de suas principais consequências o surgimento da noção de cidadania e de direitos.

\section{METODOLOGIA}

Esse trabalho se utiliza de uma abordagem qualitativa e se caracteriza como uma pesquisa teórica. Para a realização deste estudo, foram utilizados os referenciais bibliográficos principalmente livros e artigos - referentes ao surgimento do modelo econômico liberal, assim como a formação do Estado Moderno.

\section{RESULTADOS}

As raízes do capitalismo remontam ao século XII, período denominado na História ocidental de Baixa Idade Média. Como escreve Comparato (2011), o surgimento do capitalismo provocou uma ruptura radical na mentalidade que até então se caracterizava por:

[...] um sentimento de permanente insegurança diante dos múltiplos perigos da vida terrena, insegurança essa estendida, como não poderia deixar de ser, à perspectiva de uma sobrevivência além-túmulo. Daí o prevalecimento de uma visão sobrenatural da vida humana, em que à tradição do culto cristão mesclavam-se, intimamente, crenças e práticas de magia. (COMPARATO, 2011, p. 257).

Dessa forma, as tradições religiosas pouco a pouco passaram a ser questionadas, e o Mundo Antigo começava a dar lugar ao Mundo Novo, cujos valores se impõem de forma oposta aos do passado. (COMPARATO, 2011). É importante frisar que o desenvolvimento tecnológico favoreceu, de certa forma, essa mudança da mentalidade medieval, uma vez que durantes os séculos XII e XV houve grande desenvolvimento das ciências que por sua vez possibilitou o surgimento de diversos equipamentos, que foram utilizados no aperfeiçoamento da agricultura e principalmente das navegações. São criações desse período: 
[...] a bússola (mencionada pela primeira vez em 1195), os navios a vela sem remadores, as lentes oculares, os portulanos ou primeiras cartas marítimas, o emprego do carvão na indústria, os altos fornos metalúrgicos, o uso do vidro na aparelhagem científica, o relógio mecânico, o moinho eólio, a caravela, os caracteres móveis de imprensa. (COMPARATO, 2011, p. 258).

Ainda no contexto de ascensão do capitalismo, a partir do século X, os chamados burgos, ou seja, "[...] os centros de câmbio dos limitados volumes de produtos que excediam as necessidades de subsistência [...] transformaram-se em florescentes cidades e passaram a reivindicar maior autonomia junto aos senhores feudais". (ALVES, 2007, p. 78).

É válido destacar que nesse momento a classe burguesa inicia lutas com o objetivo de romper as barreiras impostas pelos senhores feudais com vistas a favorecer o desenvolvimento do comércio em seus primórdios, surgindo assim, o que Alves (2007) denomina de liberalismo ${ }^{1}$ enquanto visão de mundo.

[...] o significado que o liberalismo foi ganhando, ao longo da fase de transição da sociedade feudal para a sociedade capitalista é indissociável da luta pela liberação dos negócios burgueses em face dos entraves feudais. Os avanços conseguidos pela burguesia nessa fase, sempre expressaram, concretamente, a superação de um ou mais desses entraves. [...] o liberalismo, enquanto visão de mundo impregnou todos os campos de atividade da burguesia e todas as ações burguesas. (ALVES, 2007, p.79).

Entre os séculos XVI e XVIII - período histórico conhecido como Idade Moderna ${ }^{2}$ - o mundo ocidental, como destaca Souza (2009), assistiu a passagem efetiva da sociedade feudal para a capitalista. E, segundo Couto (2010, p. 38), tem início a derrocada do absolutismo e o surgimento dos primeiros direitos individuais:

É na luta contra o absolutismo, o poder do rei e da igreja que surge nos séculos XVII e XVIII, o reconhecimento de que o homem é portador de direitos. Desses direitos, reconhecidos como individuais, eram portadores homens livres e autônomos e deviam ser exercidos contra o poder do Estado, sendo produto de uma sociedade conformada pelo ideário liberal.

Outro aspecto importante no período foi a formação do "Estado Nacional" moderno:

À organização do aparato burocrático-institucional do Estado correspondeu a emergência de uma concepção de relação entre os homens sem precedentes na história da humanidade. Somente no Estado moderno tiveram lugar as ideias de democracia como valor universal e de cidadania como expressão do direito de todos, entre eles o direito à segurança, à liberdade e à educação. Ao Estado

\footnotetext{
${ }^{1}$ Como o próprio autor recomenda, embora a visão de mundo liberal surja nesse contexto, o liberalismo enquanto doutrina somente será formalizado ao final do século XVII, sendo consolidado plenamente no século XVIII.

${ }^{2}$ De acordo com Souza (2009), nesse contexto o termo "moderno" se referia à contraposição do novo em relação ao antigo. 
moderno foi atribuída a tarefa não apenas de normatizar as relações sociais, mas também de assegurar que os regulamentos estabelecidos deveriam ter a mesma validade para todos. (SOUZA, 2009, p. $115-116$ ).

De acordo com Couto (2010), Adam Smith ${ }^{3}$ postulava que as funções principais do Estado seriam: em primeiro lugar, a proteção da nação frente aos ataques de outras nações; a criação de mecanismos que impedissem a opressão e a injustiça entre os homens; a implantação de um aparato organizacional visando o bem comum. Nesse ponto é importante destacar que os liberais não consideravam como injustiça a exploração da força de trabalho, uma vez que os direitos civis e políticos estivessem garantidos. Desse modo, "o Estado moderno foi, portanto, estruturado para defender a política econômica do capitalismo emergente". (DALAROSA, 2009, p. 198).

\section{DISCUSSÃO}

Conforme sugere Souza (2009), a partir do século XVIII se consolidará o ideal de cidadania universal, ou seja, para além do simples reconhecimento de deveres e direitos, passando "a ser reivindicada para todos os indivíduos indistintamente". (SOUZA, 2009, p.141). Nesse sentido, caberia ao Estado a função de normatizar as relações sociais e também de assegurar a efetivação de direitos a todos. Para Souza (2009, p. 142):

Além de universal, essa nova noção de cidadania trazia outro elemento fundamental. Ela exigia que os regulamentos da vida social fossem produtos da vontade coletiva e expressos em leis. Isso quer dizer que o povo deveria ser soberano para decidir sobre seus destinos. No novo contexto de democracia que então se constituía, essa vontade coletiva ou soberania popular poderia se expressar diretamente pelo povo reunido em assembleia ou por meio de representantes eleitos pelos próprios cidadãos.

Vieira (2007) assinala que a cidadania, nesse contexto, evoca a noção de que a sociedade representa um bem disponível a todas as pessoas e que os homens são possuidores de direitos protegidos por uma lei comum. Essa nova forma de organização política, se remete a primeira Declaração dos Direitos do Homem e do Cidadão (1789), assentada na tríade da Liberdade, Igualdade e Fraternidade. Princípios esses defendidos "pelos revolucionários franceses como patamar de vida para todos os cidadãos, em qualquer país, difundindo a ideia do liberalismo para

\footnotetext{
3 “Um dos mais importantes teóricos clássicos do liberalismo [...] economista escocês que viveu nos anos de 1723 a 1790 . Sua principal obra foi $A$ riqueza das Nações: investigação sobre sua natureza e suas causas, publicada em 1776 . Sua vida e produção intelectual coincidem com a Revolução Industrial e com os anseios da burguesia inglesa. É por isso que todo seu pensamento ressalta o individualismo e afirma que o bem-estar e a economia são gerados pela "mão invisível" do mercado. Daí defender a livre-concorrência como principio econômico e colocar como tese fundamental a rejeição estatal na economia, na época, contra o mercantilismo." (DALAROSA, 2009, p. 198).
} 
o mundo". (COUTO, 2010, p. 39). Esses três princípios, aliás, representam a síntese do conceito burguês de cidadania. (DALAROSA, 2010, p.198).

Impulsionado pela crença na razão e no método científico moderno ${ }^{4}$, o século XVIII simboliza, portanto, um período de grandes conquistas da burguesia, entre as quais se destacam as mudanças econômicas sintetizadas pelo que se convencionou chamar de Revolução Industrial, e as transformações políticas provocadas a partir da luta pela Independência dos Estados Unidos e da Revolução Francesa. (SOUZA, 2009).

Conforme esclarece Vieira (2009), o século XVIII assistirá ainda a expansão do industrialismo e da filosofia que o sustenta, o chamado liberalismo. Nesse sentido o pensamento liberal pode ser entendido como:

Expressão do industrialismo, o pensamento liberal consagra as liberdades individuais, a liberdade de empresa, a liberdade de contrato, sob a égide do racionalismo, do individualismo e do não intervencionismo estatal na esfera econômica e social. Consagra, além disto, a liberdade de mercado, fazendo-o reinar soberanamente, elevado a um dom da natureza, responsável pela lei da oferta e da procura. A naturalização do mercado e de sua lei coloca ambos em situação distante, se não impossível, de sofrerem alteração por obra dos homens, afinal eles são obra da natureza. (VIEIRA, 2009, p. 186).

Diante das reflexões apresentadas foi possível observar que o capitalismo, ao contrário do que muitos acreditam, ou preferem acreditar, surgiu no contexto mundial em um determinado momento da história da humanidade. Portanto, longe de ser algo natural, o capitalismo é antes de tudo uma construção histórica, política e social que remete às lutas da emergente burguesia contra a hegemonia do poder da igreja e do absolutismo.

Para se livrar do julgo dessas instituições a burguesia traz em sua luta a noção de liberdade e de cidadania. A noção de liberdade por sua vez se consolida através da doutrina filosófica denominada de liberalismo, que afirma não só os direitos individuais como também o livre comércio. Para Orso (2007) "sua base, portanto, encontra-se radicada principalmente na propriedade privada dos meios de produção, na competição, na concorrência, no individualismo, e na defesa da liberdade de consciência e do livre mercado. (p. 165).

Assim o liberalismo se apresenta como a expressão filosófica burguesa que busca justificar e fundamentar o modo de produção capitalista.

\footnotetext{
${ }^{4}$ Alves (2007) afirma que no âmbito da ciência moderna, “[...] a busca da verdade já não seria o elemento determinante das investigações dos cientistas burgueses, mas sim o que seria útil ou desejável ao capital". (ALVES, 2007, p. 81). 


\section{CONCLUSÃO}

Apesar de as sociedades pós-modernas terem sido estruturadas numa fase pós-industrial, em que o capitalismo se renova através do avanço tecnológico e se impõe para o mundo por meio do processo de globalização e do neoliberalismo, percebe-se que sua atual formatação ainda se vincula ao pensamento e aos ideais que o fundamenta, ou seja, ao liberalismo. Uma vez que se verifica, cada vez mais, o esvaziamento dos direitos humanos em face da liberdade total dada ao mercado financeiro e econômico.

No atual contexto o cidadão é visto apenas como consumidor e os direitos sociais são entendidos como mercadorias. Ou seja, sua garantia se dá através da sua capacidade de adquirir no livre mercado. "Se não possui condições de comprá-los, deverá acessá-los através da benevolência da sociedade [...]". (COUTO, 2010, p. 73).

Mesmo com a crescente mercantilização dos direitos individuais, Alves destaca que:

O pensamento liberal clássico está hoje incorporado ao patrimônio cultural da humanidade e não há como nem por que desqualifica-lo. Mas é bom que se diga, isso é verdadeiro para essa época de transição do feudalismo para o capitalismo. O fato de a burguesia lutar pelas liberdades individuais, nessa fase, não pode levar a generalização de que, então a luta por essas liberdades seria o apanágio de toda a sua existência. (ALVES, 2007, p. 80).

Dessa forma, entende-se que a luta pelas liberdades individuais se apresenta como uma importante conquista da humanidade, no entanto não se deve acreditar que a liberdade se restrinja às bandeiras individuais, sobretudo quando essa se relaciona a supremacia da liberdade de comércio, pois como destaca o jornalista uruguaio Eduardo Galeano (2011), foi em nome do livre comércio, aliás, que a Europa justificou a venda de "carne humana" no tráfico de escravos.

Portanto, o atual momento pede não só liberdade, mas que a mesma seja orientada pelo paradigma da igualdade, que embora seja um dos pilares da revolução francesa, ainda no século XXI não foi plenamente efetivada.

\section{REFERÊNCIAS}

ALVES, G. L. O liberalismo e a produção da escola pública moderna. In: LOMBARDI, J. C.; SANFELICE, J. L. (Orgs.). Liberalismo e Educação em debate. Campinas: Autores Associados, Histedbr, 2007, p. 61-86.

COMPARATO, F. K. Capitalismo: civilização e poder. Estudos Avançados. São Paulo, vol. 25, n. 72, 2011, p. 251-276.

COUTO. B. R. $\mathbf{O}$ direito social e a assistência social na sociedade brasileira: uma equação possível? 4. Ed. São Paulo: Cortez, 2010. 198 p. 
DALAROSA, A. A. Globalização, Neoliberalismo e a Questão da Transversalidade. In: LOMBARDI, J. C. (Org.). Globalização, pós-modernidade e educação. Campinas: Autores Associados: HISTEDBR; Caçador, SC: UnC, 2009, p. $197-217$.

GALEANO, E. H. De pernas pro ar: a escola do mundo ao avesso. Porto Alegre: L\&PM Editores, 2011. $371 \mathrm{p}$.

SOUZA. J. V. A. de. Introdução à Sociologia da Educação. 2 ed. Belo Horizonte: Autêntica, 2009. $191 \mathrm{p}$.

VIERA, E. Os direitos e a política social. 2. ed. São Paulo: Cortez, 2007. 224 p. 